\title{
The Evaluation and Spatial Differentiation of Forestry Efficiency in Si- chuan Province--Based on DEA-MI Model
}

\author{
Chao Yu and Mei Li \\ Forestry College of Sichuan Agriculture University, Wenjiang, Sichuan, China
}

\begin{abstract}
Key words: Forestry efficiency; DEA; Malmquist index; Sspatial difference; Efficiency evaluation Abstract: By the DEA and Malmquist index model, the article studied the dynamic change and spatial difference of the forestry efficiency to 21 cities (States) in Sichuan province during 20052014, and revealed the change law of forestry efficiency. The results show that: 1)Forestry efficiency showed the characteristic of wave growth, but the increase was small in Sichuan Province, the city(state) number of increasing or de-creasing for forest scale returns had a wide fluctuation. The total factor productivity index of forestry was more than 1 in the whole provinc, and forest had realized the positive growth of productivity. (2)The efficien-cy of forestry in Sichuan Province presented that the Chengdu region, the Chuannan region and the Chuan-dong region were relatively higher, the Panxi region and the Chuanxibei region were relatively lower, and it had a larger regional gap during regions. The development level of Sichuan forestry efficiency was divided in-to 4 types, which were high efficiency and growth type, high efficiency and descending type, low efficiency and growth type, low efficiency and descending type, the cities(states) of high efficiency and growth type were mainly distributed in the Chengdu region and the Chuandong region, and there was a tendency to gradually reduce the difference during regions.
\end{abstract}

\section{Introduction}

In recent years, forestry has experienced logging economy stage, market economy stage, ecological construction stage in China, has broke the traditional industry to provide the first category of raw materials, and forestry diversification trend is gradually obvious. On the background of the continued growth in forestry development, there was a big difference between the industrial input and output capability of the regional forestry development process, didn't match of the use and allocation of input elements and allocation of forestry output, and had a phenomenon of investment redundancy or the use of low efficiency, and so on. By analysing the existing literature of forestry input and output efficiency, the paper found that foreign study mainly focused on the micro and meso discussion, the researching objects mainly included the public welfare forestry or forestry enterprise (Labell G, et al., 1998; Viitala, et al., 1998; Lee J Y, 2005; Lee J Y, 2008), researching the technical efficiency level and efficiency redundancy of forestry industry (Labell G, et al., 1998), allocation efficiency of forestry production factor(Viitala, et al., 1998; Neda S, et al., 2006), input and output efficiency of forestry management(Shiba M, 1997; Peter Clinch J, 2000,). The main researching methods were DEA(Lee J Y, 2005; Lee J Y, 2008; Shiba M, 1997), SFA(Lee J Y, 2005), DEA-CCR and DEA-BCC(Lee J Y, 2008), and the price method and production function(Neda S, et al., 2006). But the research on forestry efficiency in China started late, and the perspective of research was different to foreign research. The research objects mainly focused on the national forestry efficiency(Li Chunhua, et al., 2011; Song Changming, et al., 2012), the local forestry efficiency(LAI Zuo-qing et al., 2008), the efficiency of forestry enterprises and forestry(Li Lin, et al., 2012), the efficiency of farmers forestry(Zheng Yifang, et al., 2011; Huang Senwei, et al., 2011), and the main research methods were DEA, SFA method, Malquisty index, C-D production function method. Through the research of forestry efficiency at home and abroad, the paper found that there were few scholars researching on forestry combining static efficiency, and lacked to use DEA and Malmquist index to study the forestry efficiency. Therefore, according to forestry situation of 21 cities (states) in Sichuan province, the paper uses the DEA and Malmquist index model to evaluate the dynamic changes of forestry efficiency in Sichuan Province. 


\section{Research design}

\subsection{Research methods}

\subsubsection{DEA Model}

Data Envelopment Analysis (DEA for short) proposed by Charnes and Cooper, two distinguished operational research experts, is an important offshoot of operational research(HOU Xiang, et al., 2010). By introduction of the relative efficiency change, the research method can be widely applied into various fields only if the input and output indexes conform with the mathematics model and axiom system. The working mechanism is as follows: supposing $\mathrm{n}$ decision making units in an model, the input and output vector of the number $\mathrm{j}$ decision making unit is respectively: input vector $\mathrm{x}_{\mathrm{j}}=$ $\left(x_{1}{ }^{j}, x_{2}{ }^{j}, x_{3}{ }^{j}, x_{4}{ }^{j}, \ldots, x_{m}{ }^{j}\right)$, output vector $y^{j}=\left(y_{1}{ }^{j}, y_{2}{ }^{j}, y_{3}{ }^{j}, \ldots, y_{n}{ }^{j}\right), j=1,2, \ldots, n$; herein, $\left(x^{j}, y^{j}\right) \in T, T$ is Production Possibility Set(WEI Quanling, 2004).

$$
\left\{\begin{array}{c}
\min \left[\theta-\varepsilon\left(\hat{e}^{T} s^{-}+e^{T} s^{+}\right)\right] \\
\text {s.t. } \sum_{j=1}^{n} x_{j} \lambda_{j}+s^{-}=\theta x_{0} \\
\sum_{j=1}^{n} y_{j} \lambda_{j}-s^{+}=y_{0} \\
\lambda_{j} \geq 0, j=1,2, \ldots, n \\
s^{-} \geq 0, s^{+} \geq 0 \\
\sum_{j=1}^{n} \lambda_{j}=1
\end{array}\right.
$$

In this formula, $\theta(0<\theta \leq 1)$ stands for Comprehensive Efficiency, $\lambda_{j}\left(\lambda_{j} \geq 0\right)$ for Weighted Variable, $s^{-}$ $\left(s^{-} \geq 0\right)$ for Slack Variable, $s^{+}\left(s^{+} \geq 0\right)$ for Remaining Variable, $\varepsilon$ for Non-Archimedean Infinitesimal, $\mathrm{e}_{1}{ }^{\mathrm{T}}=(1,1, \ldots, 1) \in \mathrm{E}_{\mathrm{m}}$ for $\mathrm{m}$-dimension Unit Vector Space, $\mathrm{e}_{2}{ }^{\mathrm{T}}=(1,1, \ldots, 1) \in \mathrm{E}_{\mathrm{k}}$ for k-dimension Unit Vector Space. Herein, ${ }^{\widehat{T}}=(1,1, \ldots 1) \in \mathrm{E}_{\mathrm{m}}, \mathrm{e}^{\mathrm{T}}=(1,1, \ldots 1) \in \mathrm{R}_{\mathrm{k}}$.

Optimal value can be achieved upon the results calculated as $\Theta=1$ or $\mathrm{SE}=1$ and then ( $\left.\mathrm{x}_{0}, \mathrm{y}_{0}\right)$ is the optimum solution which means the pure technical efficiency and optimal scale efficiency reach the optimum value and that the input has gained the most output.

\subsubsection{Malmquist Index Model}

Total factor productivity (TFP) refers to the economic growth rate which is caused by the other inputs factors besides labor and capital, and it can be divided into three indicators, which are technical efficiency change, technological change and scale efficiency change(Botti L, et al., 2009). Therefore, the paper uses the Malmquist index (MI), which's formula as follows:

$M_{i}\left(x^{t+1}, y^{t+1} ; \mid x^{t}, y^{t}\right)=\left[\frac{D_{i}^{t}\left(x^{t}, y^{t}\right)}{D_{i}^{t}\left(x^{t+1}, y^{t+1}\right)} \times \frac{D_{i}^{t+1}\left(x^{t}, y^{t}\right)}{D_{i}^{t+1}\left(x^{t+1}, y^{t+1}\right)}\right]^{\frac{1}{2}}$

$\left(x^{t}, y^{t}\right)$ represents the input and output vectors of the t period. $\left(x^{t+1}, y^{t+1}\right)$ epresents the input and output vectors of the $t+1$ period. $D_{i}^{t}\left(x^{t}, y^{t}\right)$ and $D_{i}^{t+1}\left(x^{t+1}, y^{t+1}\right)$ respectively represents the distance function of the $\mathrm{t}$ period and $\mathrm{t}+1$ period. When $M_{i}>1$, it indicates that TFP is growing, and the efficiency is improved; When $M_{i}<1$, it indicates that TFP is reduced, and the efficiency is decreased; When $M_{i}=1$, it indicates that TFP is nvariant, and the efficiency is stable. At the same time, TFP can be decomposed into the product of technological progress and technical efficiency change, and it has the same change trend of the comprehensive efficiency change, technical efficiency change, scale efficiency change, pure technical efficiency change, technological progress change. 


\subsection{Index selection and data sources}

On the basis of the domestic and foreign related research, the input and output data of the forestry production unit can be reflected to truly and effectively assess the forestry efficiency and total factor productivity evaluation. Basic production factors in the economic sense usually include land, labor and capital. Because the forest area is an important place for the development of forestry, which is the material carrier of forestry activities; investment in fixed assets who reflects the scale and structure of forestry investment to a certain extent, is the motive power of the development of forestry; forestry personnel is an important condition for the development of forestry industry in the process, and it is the direct operator of forestry industry development. Therefore, the paper selects the forest area, investment in fixed assets and number of employees as the forestry forestry development efficiency measurement, and selects forestry output value as output index, All index data are derived from "Statistical yearbook of Sichuan province", " Forestry statistical yearbook in Sichuan province ", statistical bulletin of national economic and social development of 21cities(states) in Sichuan Province during 2005 - 2014.

\section{Results analysis}

\subsection{General characteristics of forestry development efficiency in Sichuan Province}

From table 1, the level of forestry development efficiency wasn't high in Sichuan Province, which only reached 0.509 , but the space to enhance was also large. The average technical efficiency and scale efficiency were 0.642 and 0.745 respectively, and the optimal efficiency was $64.2 \%$ and $74.5 \%$ respectively. Only the comprehensive efficiency of Chengdu forestry reached the optimal level of efficiency in 2005. The pure technical efficiency which reached the optimal level of efficiency were Chengdu, Deyang and Suining, and the scale efficiency reached the optimal level of efficiency was only Chengdu. There were 4 cities to achieve the best comprehensive efficiency level, which were Chengdu, Suining, Meishan, Ziyang in 2014. There were seven cities to achieve the best pure technical efficiency level, which were Chengdu, Deyang, Guangyuan, Suining, Neijiang, Meishan, Ziyang. There were five cities pure to achieve the best technical efficiency leve, which were Chengdu, Luzhou, Suining, Meishan, Ziyang. The research results show that there was much room for improvement of forestry input and output efficiency in Sichuan Province.

Table 1. The efficiency indexes of forestry in Sichuan Province during 2005 2014

\begin{tabular}{ccccccc}
\hline Year & $\begin{array}{c}\text { Comprehen- } \\
\text { sive efficiency }\end{array}$ & $\begin{array}{c}\text { Pure tech- } \\
\text { nical effi- } \\
\text { ciency }\end{array}$ & $\begin{array}{c}\text { Scale effi- } \\
\text { ciency }\end{array}$ & $\begin{array}{c}\text { Increasing re- } \\
\text { turns to scale }\end{array}$ & $\begin{array}{c}\text { Constant re- } \\
\text { turns to scale }\end{array}$ & $\begin{array}{c}\text { Decreasing returns } \\
\text { to scale }\end{array}$ \\
\hline 2005 & 0.268 & 0.497 & 0.428 & 20 & 0 & 1 \\
2006 & 0.244 & 0.549 & 0.375 & 20 & 0 & 1 \\
2007 & 0.527 & 0.606 & 0.864 & 18 & 0 & 3 \\
2008 & 0.682 & 0.705 & 0.95 & 10 & 3 & 8 \\
2009 & 0.656 & 0.729 & 0.872 & 12 & 3 & 6 \\
2010 & 0.635 & 0.707 & 0.882 & 11 & 4 & 6 \\
2011 & 0.479 & 0.592 & 0.764 & 13 & 4 & 5 \\
2012 & 0.551 & 0.658 & 0.812 & 14 & 2 & 6 \\
2013 & 0.535 & 0.661 & 0.794 & 12 & 3 & 5 \\
2014 & 0.513 & 0.715 & 0.712 & 15 & 1 & 5 \\
mean value & 0.509 & 0.642 & 0.745 & 14 & 2 & \\
\hline
\end{tabular}

\subsection{The change of forestry development efficiency in Sichuan Province}

From table 2, it can be known that the efficiency of forestry development showed the characteristics of fluctuating growth in Sichuan Province during 2005-2014, and the overall situation had a upward trend, but the increase rate was small. The total factor productivity index of forestry was 1.162 , with 
an average annual growth of $16.2 \%$ in Sichuan Province during 2005-2014. The total factor productivity index was greater than 1, and achieved a positive growth rate in Sichuan Province. From the change of comprehensive efficiency, pure technical efficiency and scale efficiency, pure technical efficiency and scale efficiency, forestry comprehensive efficiency change index and pure technical efficiency were more than 1 of most cities(states) in Sichuan Province. But only in Chengdu, Zigong, Deyang, the comprehensive efficiency change index were 1, 0.944 and 0.961, and the technology level changes was 0 or negative. The research results showed that the main reason of forestry comprehensive efficiency increase was the change of pure technical efficiency in Sichuan Province, and the improvement of forestry comprehensive efficiency was related to technological change and technological development in Sichuan Province.

Table 2. The efficiency change index of 21 cities(states) in Sichuan Province during 2005 2014

\begin{tabular}{llllll}
\hline & $\begin{array}{l}\text { com- } \\
\text { prehen- } \\
\text { sive ef- } \\
\text { ficienc }\end{array}$ & $\begin{array}{l}\text { Tech- } \\
\text { nologi- } \\
\text { cal } \\
\text { pro- } \\
\text { gress }\end{array}$ & $\begin{array}{l}\text { Pure } \\
\text { tech- } \\
\text { nical } \\
\text { effi- } \\
\text { ciency }\end{array}$ & $\begin{array}{l}\text { Scale } \\
\text { effi- } \\
\text { cien- } \\
\text { cy }\end{array}$ & $\begin{array}{l}\text { Total } \\
\text { factor } \\
\text { produ } \\
\text { ctivi- } \\
\text { ty }\end{array}$ \\
\hline Chengdu & 1.000 & 1.122 & 1.000 & 1.000 & 1.122 \\
Zigong & 0.944 & 1.083 & 0.931 & 1.014 & 1.022 \\
Panzhihua & 1.221 & 1.036 & 1.078 & 1.133 & 1.112 \\
Luzhou & 1.227 & 1.000 & 1.052 & 1.166 & 1.227 \\
Deyang & 0.961 & 1.185 & 1.000 & 0.961 & 1.138 \\
Mianyang & 1.107 & 1.065 & 1.003 & 1.103 & 1.179 \\
Guangyuan & 1.440 & 1.014 & 1.163 & 1.238 & 1.46 \\
Suining & 1.007 & 1.199 & 1.000 & 1.007 & 1.208 \\
Neijiang & 1.079 & 1.016 & 1.029 & 1.049 & 1.097 \\
Leshan & 1.114 & 1.065 & 1.033 & 1.078 & 1.186 \\
Nanchong & 1.035 & 1.067 & 1.049 & 0.986 & 1.105 \\
Meishan & 1.277 & 1.121 & 1.114 & 1.146 & 1.431 \\
Yibin & 1.131 & 1.021 & 1.011 & 1.119 & 1.154 \\
Guangan & 1.083 & 1.082 & 1.065 & 1.017 & 1.172 \\
Dazhou & 1.314 & 1.029 & 1.129 & 1.164 & 1.352 \\
Yaan & 1.180 & 1.262 & 1.119 & 1.055 & 1.49 \\
Bazhong & 1.239 & 1.031 & 1.092 & 1.135 & 1.278 \\
Ziyang & 1.026 & 1.212 & 1.019 & 1.007 & 1.244 \\
Aba & 1.048 & 1.039 & 1.037 & 1.011 & 1.089 \\
Ganzi & 1.118 & 1.109 & 1.085 & 1.030 & 1.240 \\
Liangshan & 1.159 & 1.046 & 1.046 & 1.108 & 1.213 \\
Mean val- & 1.129 & 1.037 & 1.050 & 1.073 & 1.162 \\
ue & & & & & \\
\hline & & & & &
\end{tabular}

\subsection{Spatial distribution characteristics of forestry development efficiency in Sichuan Province}

From figure 1, it showed that the total factor productivity change index of Chengdu region, Chuannan region, Chuandong region and Chuanxibei region was greater than 1, while the change of total factor productivity index was only 0.901 in Panxi region, and it was a negative growth. Among them, the change index of forestry total factor productivity reached 1.263 in Cuandong region, and achieved an average annual growth of $26.3 \%$, which had the good efficiency of input and output, due to the joint action of the pure technical efficiency, technology efficiency and scale efficiency. The change index of forestry total factor productivity was 0.901 , with an average annual growth rate of $10 \%$ in Panxi region. The change index of the comprehensive efficiency, pure technical efficiency change index and scale efficiency change index were all larger than 1, but the change index of technical progress was 0.769 . In general, the impact of technological progress changes was the total factor productivity on the whole Panxi region of the total factor productivity, which was con- 
sistent with the effect of technological progress on total factor productivity changes in the previous paper. It showed that the forestry technology progress growth rate in Chengdu region, Chuannan region and Chuandong region were higher than Chuanxibei region andPanxi region, which made the regional forestry development efficiency not balanced. But it can reduce the redundancy of forestry inputs by the introduction of advanced forestry technology, in order to improve the efficiency of forestry development.

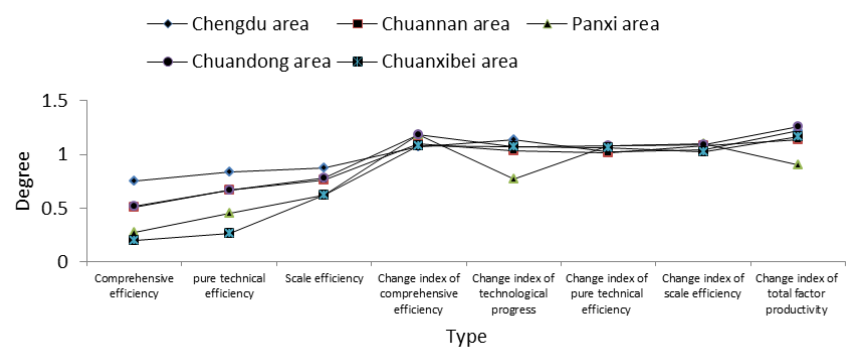

Figure 1. The efficiency change index of 21 cities(states) in in Sichuan province during 2005 2014

\section{Conclusions}

The study showed that the efficiency of forestry development had the characteristics of fluctuating growth in Sichuan Province, which the situation had the overall rise, but had a smaller increase. The forestry comprehensive efficiency of 21 cities (States) reached 0.509 in Sichuan Province. And the average technical efficiency and scale efficiency were 0.642 and 0.745 , but the level of forestry efficiency was not high, only some of 21 cities (states) achieve the best; From the change of forestry comprehensive efficiency in Sichuan Province, the cities(states) had chieved the highest overall efficiency of forestry, which were Chengdu, Suining, Ziyang, and the value was more than 0.9, but other cities(states) showed a strong volatility; The total factor productivity index of forestry was 1.162 , with an average annual growth of $16.2 \%$ in Sichuan province during 2005-2014.

The efficiency of forestry development showed that Chengdu region, Chuannan region and Chuandong region was relatively higher, Panxi region and Chuanxibei region were relatively lower in Sichuan province, and the regional disparity was relatively large. On the one hand, due to the regional differences in economy development, the pure technical efficiency showed Chengdu region, Chuandong region and Chuannan region are higher, and Chuanxibei region had low distribution situation, which resulted in insufficient scale efficiency advantages to make up the pure technical efficiency. On the other hand, the technical progress of Chuanxibei region and Panxi region of Sichuan Province was lower than the rate of change of Chengdu region, Chuandong region and Chuannan region. Therefore, the key to improve the efficiency of forestry is to improve the pure technical efficiency.

\section{References}

[1] Labell G, Stuart W B. Technical efficiency evaluation logging contractors using anon parametric model[J]. Inter Journal of Forest Engineering, 1998, 9(2): 15-24.

[2] Viitala, Esa-jussi, Hanninen, et al, Measuring the efficiency of public forestry organizations[J]. Forest Science, 1998, 44(3): 298-307.

[3] Lee J Y. Using DEA to measure efficiency in forest and paper companies[J]. Forest Products Society, 2005, 55(1): 58-66.

[4] Neda S, DR Taraneh S. Productivity and efficiency assessment of the wood industry: A review with a focus on Cannada[J]. Foerst Products Society, 2006, 56(11/12): 25-32.

[5] Lee J Y. Application of the three-stage DEA in measuring efficiency an empirical evidence[J] Applied Economics Letters, 2008, 15(1): 49-52. 
[6] Shiba M. Measuring the Efficency of Managerial and Techinical Performances in Forestry Activities by Means of DEA[J]. Inter Journal of Forest Engineering, 1997, 8(1): 7-19.

[7] Peter Clinch J. Assessing the social efficiency of temperate-zone commercial forestry programmes Ireland as a case study[J]. Forest Policy and Economics, 2000, 17(17): 225-241.

[8] Li Chunhua, Li Ning, Luo Huaying, et al. The Efficiency Analysis and Path Optimization of Forestry Input-Output in China Based on Data Envelopment Analysis [J]. Chinese Agricultural Science Bulletin, 2011, 27(19): 55-59(In Chinese)

[9] Song Changming Xiang Yulin. Study of Forestry Industry's Technical Efficiency and its Influencing Factor-Based on Stochastic Frontier Production Function Model[J]. Forestry Economics, 2012(12): 66-70(In Chinese).

[10]LAI Zuo-qing, ZHANG Zhong-hai. The Super-efficiency DEA Analysis of Guangdong Forestry Input-output[J]. Journal of South China Agricultural University( Social Science Edition), 2008(4): 43-48 (In Chinese) .

[11]Li Lin Xu Zhaojun Cao Yunkun. Measuring State Forestry Enterprise of Heilongjiang Province Production Efficiency —-Based on Three-stage DEA Model[J]. Forestry Economics, 2012(4): 51-55(In Chinese).

[12]Zheng Yifang, Xu Jiaxian, Sun Xiaoxia, et al. Comparative Analysis of Management Scale Efficiency among Three Kinds Forest in Fujian[J]. Forestry Economics, 2011(12): 53-55(In Chinese).

[13]Huang Senwei, Su Shipeng, Zhang Chunxia. Empirical Research on the Management Efficiency of Private Forest in Fujian[J]. Forestry Economics, 2011(10): 72-74(In Chinese).

[14]HOU Xiang, MA Zhan-xin1, ZHAO Chun-ying. Research on Models of the Data Envelopment Analysis[J]. Journal of Inner Mongolia Universit y, 2010, 41(5): 583-593(In Chinese).

[15]WEI Quanling. The Data Envelopment Analysis[M]. Beijing: Science Press, 2004: 15-36(In Chinese). 